\title{
On the Construction of the Precise Assistance Mechanism of "Students Facing Five Different Difficulties" based on Grid Management in Colleges and Universities
}

\author{
Lei Zhang ${ }^{\mathrm{a}}$ and Qiangwei Yan ${ }^{\mathrm{b},}$ * \\ Wuhan Textile University, Wuhan 430200, China \\ alei.zhang@wtu.edu.cn, b3858990@qq.cm
}

Keywords: Students' apartments, grid management, "students facing five different difficulties", precise assistance mechanism.

\begin{abstract}
Based on the practice of "the grid management of students" apartments", which is carried out by the Electrical and Electronic Engineering Institute of Wuhan Textile University, this paper takes the initiative to position those "students facing five different difficulties" and construct the assistance mechanism, then discusses the implementation mode of "the grid management", so as to better guarantee students' interests and rights and deepen the quality education.
\end{abstract}

\section{Introduction}

The current traditional system of management and service cannot fully meet the new requirements. There are some weaknesses in the education service management, the ideological and political courses, and the security and stability in the colleges and universities, so we must promote the informationized education and the use of modern information technology. The grid management is conducive to obtain students' information timely and comprehensively, thus improving the timeliness, pertinence and scientificity of the students' education service management. It is an effective way to realize the modernization of the governance system and the governance ability in colleges and universities.

Accurate identification of "students facing five different difficulties". (1) Students in the economic predicament: students, whose average living expenses is less than 400 yuan monthly, have difficulties in economic conditions and are frugal in their daily life; students live in the remote rural poor areas, or their parents are laid-off and without fixed source of income; orphans, disabled students, students of single-parent, and students from low-income families. (2) Students with difficulties in study: the score of failing exams reaches 10 points in the first grade; the score of failing exams reaches 20 points in the second grade; the score of failing exams reaches 30 points in the third grade. (3) Students with psychological distress: those students may have a history of suicide attempts, suffer from depression, have delusions or other psychotic symptoms and still in the medication; those lovelorn students, or with an accidental pregnancy or abortion; students with physical defects or long illness, or suffer from losing a relative or a major change in life. (4) Students with difficulties in communication: those students have a paranoid personality, feel down for a long time, or do not communicate with people; students are extremely self-abased and with poor ability to express themselves. (5) Students with difficulties in employment: employment pressure and difficulties caused by students' significant lower individual abilities than the basic requirements of employment; employment pressure and difficulties caused by low psychological qualities, including lack of employment mentality, employment psychological burden and panic, etc.; employment pressure and difficulties caused by their career attitudes and selections, which cannot meet the real social requirements and so on.

\section{Subjects and Methods}

2.1 An overview of "the grid management of students' apartments" in colleges and universities

The grid technology is an important information technology in the international world in recent years. Its goal is to realize the sharing and coordinating work of high-performance resources in the virtual 
network, and eliminate the isolated islands of information and resources. The role of the grid is "bonding" the information, information storage, and the processing capacity, that scattered on the network, together in a reasonable way to form an organic whole, to provide the processing capacity that is much more powerful any single high-performance computer, to achieve a high degree of integration and sharing of information [1]. The so-called "grid management" refers to the idea of using the computer grid management, divide the object of management into a number of grid cells according to certain standards, with the aid of modern information technology and the coordinating mechanism between each grid cell, so that each grid cell can exchange information effectively, and share the organization's resources transparently, to eventually achieve the modern management idea of the integration of organizational resources and improvement of management efficiency [2]. The assignment of responsibility uses the method of "specially designated person being responsible for particular grids" [3]. There are a total of 749 articles about "grid management" in CNKI (China National Knowledge Internet) in the recent 10 years (Table 1), which shows that the "grid management" has become a hot topic in the current academic research.

Table 1 Statistics of related works of "grid management" on Chinese Journal Net

\begin{tabular}{cccccccccccc}
\hline Year & 2016 & 2015 & 2014 & 2013 & 2012 & 2011 & 2010 & 2009 & 2008 & 2007 & 2006 \\
\hline Number & 140 & 132 & 118 & 122 & 59 & 46 & 29 & 33 & 30 & 22 & 18 \\
\hline
\end{tabular}

2.2 The construction of the precise assistance mechanism of "students facing five different difficulties"

According to the geographical and management characteristics of whole students' apartments, the apartments are divided into a number of grids, for example, if all students are accommodated in $\mathrm{N}$ buildings, it will be divided into $\mathrm{N}$ small grids. The top grid is the general administrative departments constituted by the department of student affairs, the logistic group, and the security office in the university. As for specific affairs, they are implemented by the college students' apartment management committee, which is under the jurisdiction of the general administrative departments above. Under the top grid, many apartment communities are divided, and each apartment community has a self-management committee, which is supervised by colleges and departments in the university (Fig.1). As for the horizontal: the main body of management is based on each grade, and the counselor is the first person in charge of apartments of this grade, and the direct executors are the monitor and the league secretary of each class. The vertical: the "apartment's grids" should be constructed in the first place, and the next is to set up the apartment management committee. Similarly, according to the model, the grid management should be designed, aimed at positioning those "students facing five different difficulties" maximally, and helping them in study and their daily life.

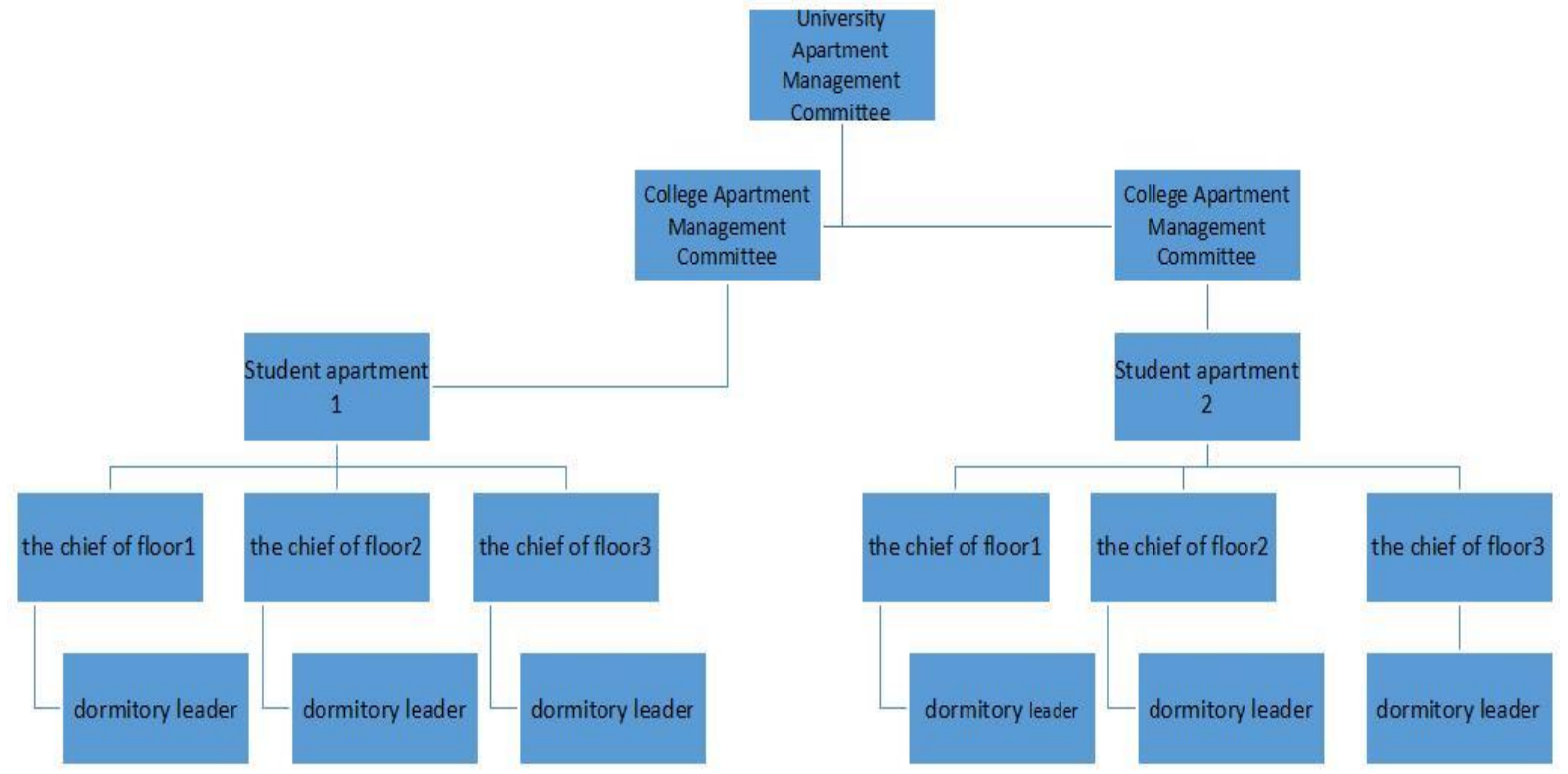

Fig. 1 "the grid management of students' apartments" in the College 


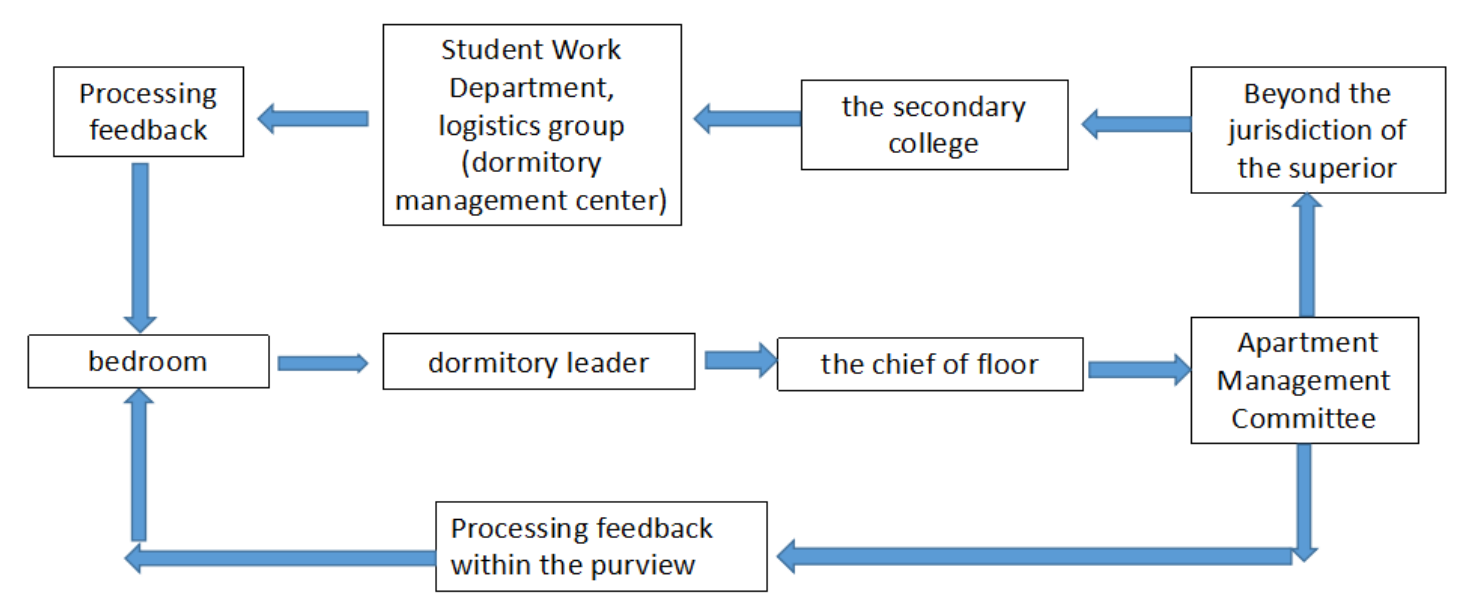

Fig. 2 The information transmission system

At present, the student management of colleges and universities focus on students' faculties and classes, and the students' apartment is only a secondary part. The management of students' apartments still remains in the exploratory stage, while the grid management is a new management model. It is a digital management model, playing a good management role on carrying out activities, collecting information, ensuring security in college students' apartments, thus it is very important to build the smooth operating mechanism of "the grid management of students' apartments". The mechanism is operated, by the hierarchical divisions, to transfer and manage information layer by layer. The lowest layer of information transmission is dormitories, and the highest is the department of student affairs and the logistics group, etc. (Fig.2). Once there are emergent public opinions about the "students facing five different difficulties", they could be spread fast and effectively in the grid system, and be dealt with in the first time.

Aimed at those "students facing five different difficulties", the college has made many regulations to help them, and counselors even do office work in the apartment to go into the students' group and know better about them. The innovation methods has achieved some results, and the students management model has gradually changed from rigid to flexible, from pure education to multiple services.

It is necessary for counselors to contact with students regularly, so that they can change their work according to the actual needs, and make the grid management staffs "go with purposes, come with problems, and return with feedbacks", that is, to change from the passive way of contact into the active way of service, to make the work more specific and effective. As for students who need to be helped in the grid, the college should adopt the way of "one helps one", to make each student could get specific help, thus helping them solve difficulties and problems. At the same time, the college should broaden the channels of contact and services, give students their contact information freely and timely, so that students who facing difficulties can contact with the staff of the grid management whenever and wherever.

\section{Summary}

The counselors' enthusiasm, initiative and creativity should be maximally brought into play, and the students' roles of leading, spreading and passing on should be further developed. Thus, the long-term mechanism of students' self-education, self-management and self-service could be formed, and "the grid management of students' apartments" could be promoted. So as to help "students facing five different difficulties" realize their dreams and reach their primes, to create a harmonious and civilized campus. 


\section{Acknowledgements}

The fine project of counselor work of Wuhan Textile University in 2016(201606). The special fund for the ideological and political education of Wuhan Textile University in 2016(No.163101). The subject project of research in colleges and universities of Hubei Province during 2017-2018 (1716ZY25).

\section{References}

[1] Foster I, Kesselman C. The Grid: Blueprint for a New Computing Infrastructure. Morgan Kaufman Publishers, 1998.

[2] Zheng Shiyuan, Xu Hui, Wang Huanchen. A Summary of Grids and the Grid Management. System Engineering, 3(2005)27-32.

[3] Wu Meng, Wang Huan. The Innovation and Dilemma of the Community Grid Management System-Based on the Investigation and Research on District S, H city. Journal of Fuyang Normal University (Edition for Social Science), 6(2012)37-40. 